\title{
Determination of fire parameters in a passenger car fire test using thermovision
}

\author{
Janusz Rybiński ${ }^{1, *}$, Anna Szajewska $^{1}$ \\ ${ }^{1}$ The Main School of Fire Service, Faculty of Fire Safety Engineering, 52/54 Slowackiego St., \\ 01-629 Warsaw, Poland
}

\begin{abstract}
The article presents results of research on the dynamics of passenger car fire development that was made at SGSP. To collect data, a fire test was conducted on a passenger car from segment A. The experiment was made in an open terrain in natural conditions. During the test basic fire parameters were determined and presented compared to other results obtained in similar tests made also at SGSP, and compared to literature data. In the test, the fire gases temperature was measured with thermocouples and the surface temperature of the car body with thermocouples and a thermal imaging camera. Events related to fire development were recorded: falling out of windows, bursts of tires, explosions of actuators and elements of the braking system that could pose a threat to third parties or firemen. Moreover, difficulties associated with temperature measurements of a burning car were presented using a thermal imaging camera, and those are closely related to the incorrect emissivity coefficient. The benefits of the thermal imaging camera in measurements of the surface temperature of the object under the fire test were shown.
\end{abstract}

\section{Introduction}

Every year, approximately 7,000 passenger car fires are recorded in Poland, including every tenth as a result of deliberate arson [1]. Car fires bring significant material damage and pose a threat to society. Understanding the course of a fire allows determining the cause of the fire. Fire signs contain evidence of possible crimes. Therefore, it is necessary to have indepth knowledge of all aspects of this type of fires for the needs of the fire brigade, police and investigation bodies.

Over the past 20 years, there have been significant developments in the use of thermal imaging in fire protection [1]. Thanks to the invention of bolometric detectors, cameras built with their use have become relatively cheap and do not require cooling, they have dramatically fewer moving mechanical parts, which makes them resistant to shocks.

Cameras have been designed for users working in a hurry, danger and stress. They are very easy to use, handy and specially adapted to work in difficult fire conditions; they are resistant to water, dust, dirt, high ambient temperature.

\footnotetext{
* Corresponding author: jrybinski@sgsp.edu.pl
} 
Fire brigades in economically developed countries are equipped with thermal imaging cameras, which are standard equipment nowadays [2-7]. In Poland, these cameras are the equipment of most Rescue and Fire Fighting Units and their number is systematically growing [8-9]. Polish firefighters value them and use eagerly. Thermal imaging cameras (TICs) are most often used when extinguishing internal fires but they are also useful for other types of rescue and firefighting operations. They can be used to measure the temperature of the surface of buildings on fire, including means of transport. This article shows how to use thermal imaging cameras to measure the temperature of an object in external fires.

Measurements of the surface temperature of the car body, and the surface temperature of glass panes, were made using thermal imaging cameras. After the experimental tests, the results of the measurements were processed in computer software.

\section{Fire test}

\subsection{Object and test conditions}

The test was carried out on a Fiat Cinquecento produced in 1995. The car had full standard equipment and was put into service. From the fire point of view, in this type of car there can be distinguished two separate rooms in which a fire develops. These are: the passenger compartment and the engine compartment. They are separated by a fire barrier that delays the fire from the engine room to the passenger compartment.

The research was carried out in the open. In external fires, weather conditions strongly affect the fire dynamics. Therefore, in the conducted fire tests, a mobile weather station was always used. During the fire test the following meteorological conditions were present:

$-7^{\circ} \mathrm{C}$ temperature,

- $1009 \mathrm{hPa}$ atmospheric pressure,

$-62 \%$ relative humidity,

- heavy clouds,

- wind speed about $3 \mathrm{~m} / \mathrm{s}$.

The wind was unstable. Its direction and speed changed. It caused the flames to blow.

\subsection{Firing a passenger cabin}

The fire was initiated on the front left tire. A piece of material was placed thereon, and 100 $\mathrm{ml}$ of gasoline was poured on the tire and set on fire. After 6 minutes the tire exploded. Plastic elements of the bumper and the reflector were set on fire. The fire got into the engine compartment. Intense combustion in the engine compartment, during which the temperature exceeded $600^{\circ} \mathrm{C}$, lasted about 13 minutes. The temperature reached a maximum of $865^{\circ} \mathrm{C}$. The temperature course of fire gases in the engine compartment is shown in Figure 1. The thermocouple was placed above the motor head. 


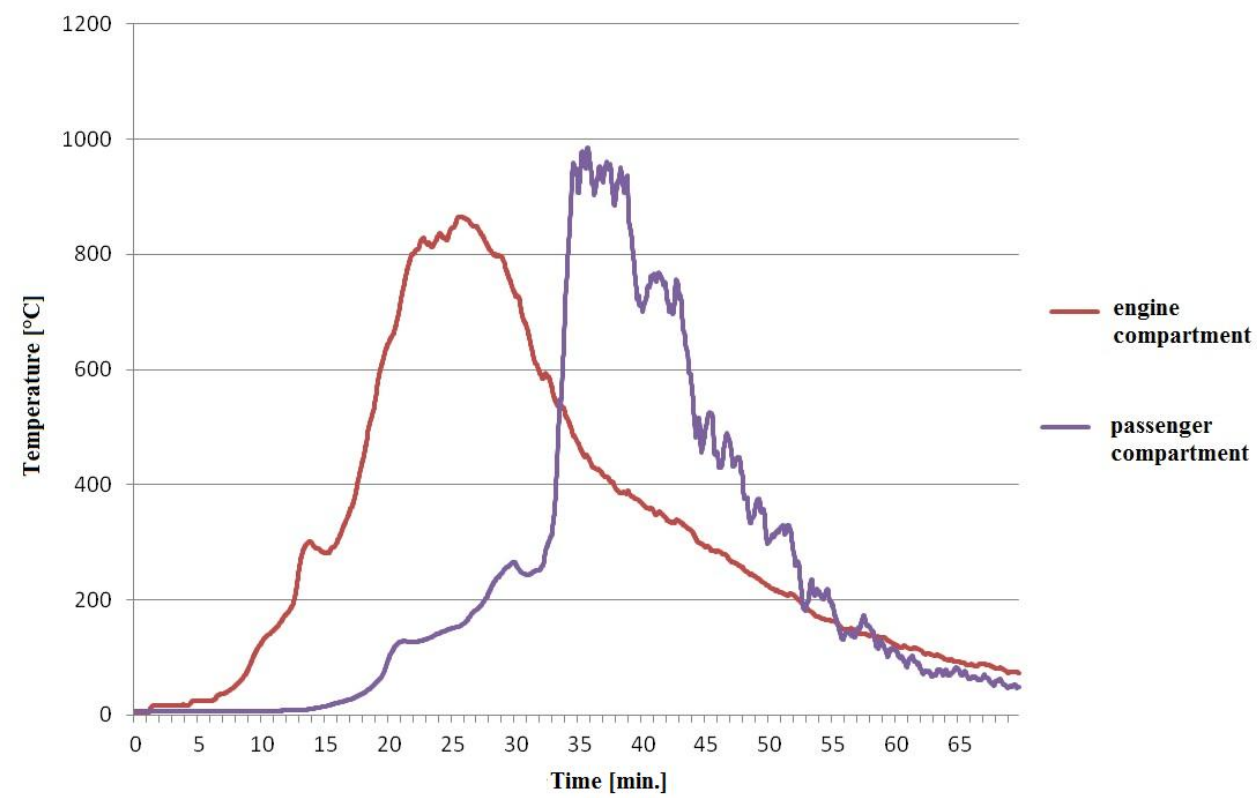

Fig. 1. Temperature graphs in the engine compartment and the passenger compartment.

After a few minutes the flames covered the windshield and then spread to the hood, causing it to crack. Before the cracking, the temperature of the pane measured with the thermal imaging camera was about $340^{\circ} \mathrm{C}$. A very narrow gap was formed, which did not significantly affect the combustion dynamics. However, it discharged mechanical stresses caused by the temperature rise, as a result of which the glass did not fall into pieces. The presence of the glass hampered the air supply and thus suppressed the increase in combustion dynamics. In the 32nd minute of the experiment that part of the windshield fell inside. The formed hole allowed the free flow of air into the interior of the vehicle. Moments before falling out, the glass temperature was around $460^{\circ} \mathrm{C}$. The falling out of the pane essentially influenced the increase of combustion dynamics. The fire destroyed the left side windows and a moment later the right side ones. The temperature in the passenger cabin increased quickly from about $300^{\circ} \mathrm{C}$ to about $950^{\circ} \mathrm{C}$. The fully developed fire phase began and lasted about 12 minutes. The maximum temperature that was recorded inside the passenger cabin was $985^{\circ} \mathrm{C}$ (Figure 1). In similar tests conducted at SGSP, a fire initiated outside the car developed similarly. Plastic and rubber elements on the car body melted and burned: gaskets, slats, bumpers, lamp fixtures. Burning plastics dripped and spread the fire on the car body. This process took place slowly, sometimes even for an entire hour. In some cases, infrared observation allows seeing more than in visible light. When the cabin was sealed, the combustion inside was very slow until the windows fell out. Therefore, the highest fire strength in a closed vehicle depends on the temperature of the glass melting (the material from which they were made). Figure 2 shows the thermal image on the thermal imaging camera's display when the side window is out.

The glass broke down into small pieces indicating that it was made of tempered glass. In some cars the windows are made of plastic. These types of glass do not break but melt and drip down. The heated glass pieces are clearly visible on the thermal imaging camera's display. They cannot be seen in visible light. The presented example shows the usefulness of thermovision in fire tests. 


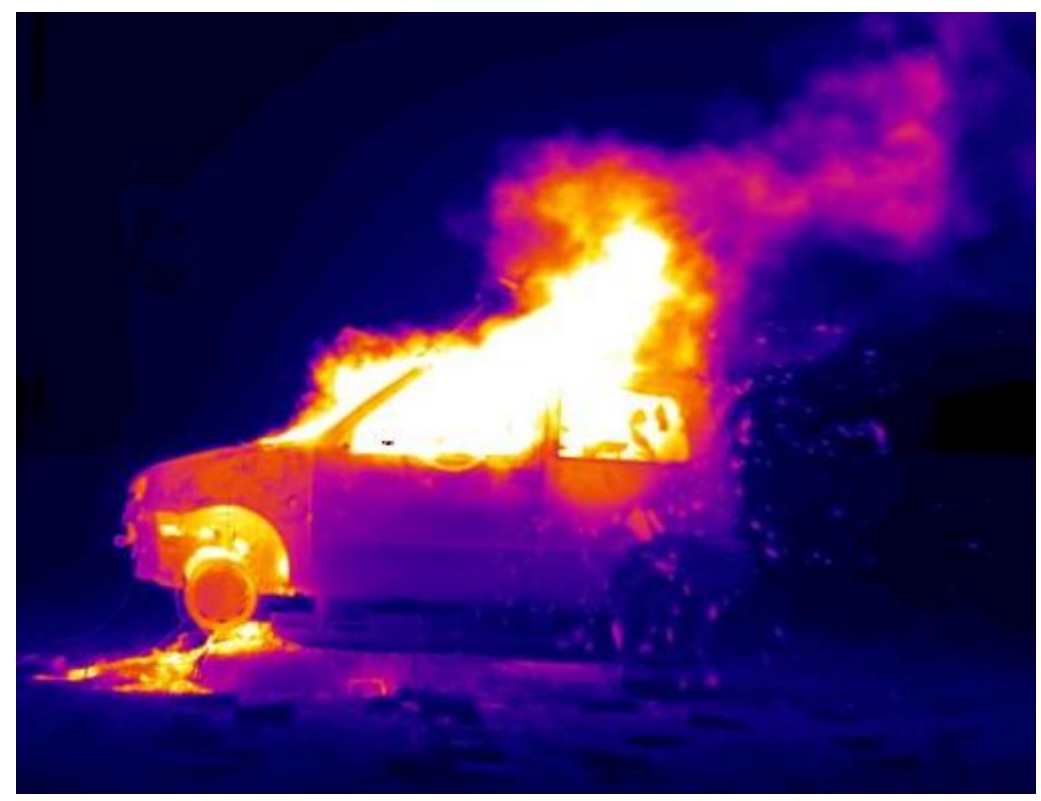

Fig. 2. The thermal image on the camera's display shows the moment when the side window fell out. There are visible hot fragments of glass.

\subsection{Fire extinguishing phase}

At 44 minutes the fire went to the decay phase. Most of the combustible materials of equipment and construction have already burnt out. The temperature inside the passenger cabin was systematically decreasing. The fire moved to the rear wheels. The tire of the spare wheel in the luggage compartment came on. After a few minutes, the tires exploded. Two sounds of explosion of the actuators were also heard. The sight of a burning car sometimes attracts outside spectators. In the final phase the fire seems less threatening. This encourages outsiders to approach a burning car. In this phase of a fire the hazards arise due to fireballs caused by the explosion of tires, metal shards caused by the explosion of actuators, shock absorbers, braking system components, fire extinguisher, etc. In this phase the tank can be unsealed, spilled and ignited, LPG gas can also be ignited.

\section{Test results}

The described test (item 1 in table 1) was one of many fire tests carried out at SGSP. Similar tests were carried out in which the combustion process was initiated from the outside. The fire course was similar. After pouring gasoline on the body and setting it on fire, the fire developed slowly on seals, battens, lamps, and tires, and only after several or several dozens of minutes it went inside the car. Table 1 presents the parameters of test fires carried out at SGSP. The following designations have been introduced:

$\mathrm{t}_{\mathrm{cab}}$ - time of intensive combustion in the passenger cabin,

$t_{\text {eng }}$ - time of intensive combustion in the engine compartment,

$\mathrm{T}_{\text {max, cab }}$ - maximum temperature in the cabin,

$\mathrm{T}_{\text {max, eng }}$ - maximum temperature in the engine compartment,

$\Delta \mathrm{m}$ - burnt mass during the test,

$\mathrm{Q}_{\mathrm{d}}$ - fire load density. 
The intensive combustion time was calculated as the time from the moment when the gases in the room have reached a temperature of $600^{\circ} \mathrm{C}$ until the moment in which their temperature decreased to $80 \%$ of the maximum value.

Table 1. Parameters of tested fires.

\begin{tabular}{|c|c|c|c|c|c|c|c|c|}
\hline Item & Made & $\begin{array}{c}\text { Year of } \\
\text { production }\end{array}$ & $\begin{array}{c}\mathbf{t}_{\text {cab }} \\
{[\text { [min] }}\end{array}$ & $\begin{array}{c}\mathbf{t}_{\text {eng }} \\
{[\mathbf{m i n}]}\end{array}$ & $\mathbf{T}_{\text {max,cab }}$ & $\mathbf{T}_{\text {max,eng }}$ & $\begin{array}{c}\mathbf{\Delta m} \\
{[\mathbf{k g}]}\end{array}$ & $\begin{array}{c}\mathbf{Q}_{\mathbf{d}} \\
{\left[\mathbf{M W} / \mathbf{m}^{2}\right]}\end{array}$ \\
\hline 1 & $\begin{array}{c}\text { Fiat } \\
\text { Cinquecento }\end{array}$ & 1995 & 12 & 13 & 985 & 865 & 144 & 1200 \\
\hline 2 & Fiat Punto & 1996 & 10 & 9 & 1043 & 863 & 150 & 1130 \\
\hline 3 & Peugeot 106 & 1995 & 11 & 12 & 989 & 1023 & 110 & 751 \\
\hline 4 & Peugeot 106 II & 1999 & 12 & 15 & 943 & 860 & 160 & 1050 \\
\hline 5 & Skoda Felicia & 1997 & 20 & 22 & 1040 & 845 & 140 & 890 \\
\hline 6 & $\begin{array}{c}\text { Opel Astra } \\
\text { hatchback } \\
+ \text { LPG }\end{array}$ & 1993 & 14 & 27 & 1060 & 885 & 180 & 1040 \\
\hline 7 & Polonez Caro & 1999 & 18 & 24 & 1037 & 823 & 155 & 880 \\
\hline 8 & Polonez Caro & 1999 & 19 & 23 & 1001 & 730 & - & - \\
\hline
\end{tabular}

Tests carried out by Okamoto K. and others [10-11], conducted on many cars, show that the maximum temperature of a passenger car fire in an open area is around $1000^{\circ} \mathrm{C}$. The combustion times were comparable to the times obtained in the carried out tests, presented in Table 1. Other researchers received similar results [12-14]. Shipp M. and Spearpoint M. [15] conducted experimental tests on mid-size cars in conditions that simulated a tunnel with good ventilation. The maximum gases temperature was $1250^{\circ} \mathrm{C}$. It is observed that the fire dynamics of newer cars is greater than those produced earlier. Newer production cars are burning more intensively because in the construction and equipment of newer cars, the percentage of plastics is clearly larger [16].

\subsection{Temperature of window panes}

The free flow of oxygen is the main factor influencing the fire dynamics of a car. In the presented test, the fire developed in conditions of limited air access in the flashover phase and free air access after flashover. It was conditioned by the behaviour of the window panes. Until the flashover the passenger compartment was leakproof, so the lack of oxygen suppressed the combustion process. Figure 3 shows the distribution of isotherms in the Fiat Cinquecento at the $32 \mathrm{nd}$ minute of combustion just before the side windows fell out. Isotherms illustrate not only the temperature gradient, but also the stress gradient caused by the thermal expansion of the glass. 


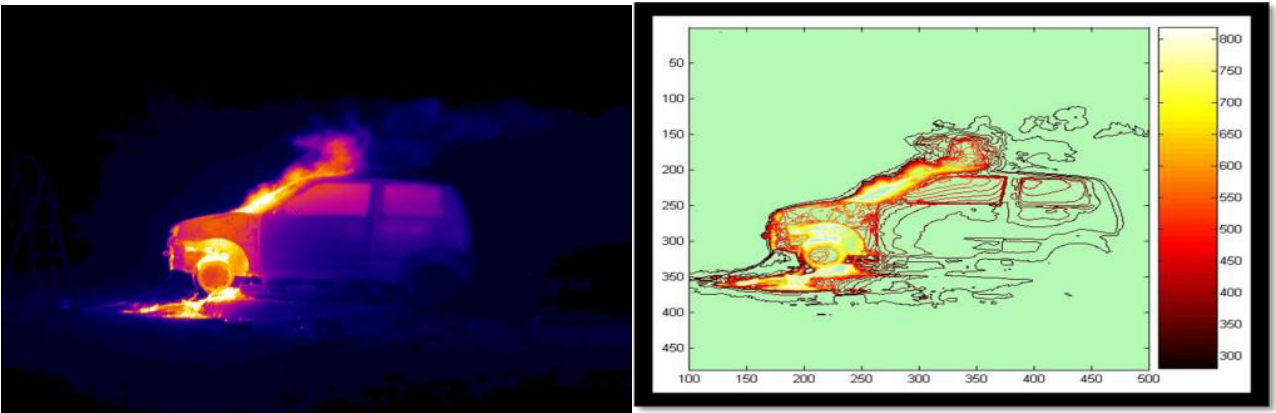

Fig. 3. Isotherms on the surface of the car body before the side windows fell out.

The situation changed after the windows fell out. The air flowed into the interior, increasing the burning rate. The moment of falling out of windows is of key importance for the fire development, because it is associated with a rapid increase in fire strength. Observation of the windows can give information when this occurs and warn the firemen against the danger of flashover. The cars have two types of glazing, which behave differently in a fire. Glass panes made of plastics that easily soften and dissolve in lower temperatures as well panes made of tempered glass that break in a fire into small pieces. Tempered glass panes are more resistant to high temperatures. Their destruction is not caused by a high temperature value, but by internal mechanical stresses. For research purposes, the temperature of the glass can be measured with a thermocouple with a very small heat capacity. A thermocouple connector made of thin wires is glued onto the glass surface. In static conditions, such a measurement gives reliable results, but in dynamic conditions the results may be subject to a significant error. Moreover, the temperature gradient can be recorded on the surface of the hot glass with the camera, and the internal stresses of the glass can be determined using appropriate software. However, a disadvantage of such measurement is the need to know the emissivity of the surface. In fire conditions, only approximate emissivity can be determined. To a much lesser extent, the measurement error refers to the difference in temperature. The condition of the panes after the fire gives information about its course and causes. That is why window testing is so important. Glass tests at the fire site can give information on whether there were explosions in the fire zone. It can help to determine directions of fire propagation and determine the place of fire initiation. It can allow determining the maximum temperature value in specific places.

\subsection{Emissivity of the car body}

When measuring the temperature, the emissivity of the object needs to be known [17]. During the fire, additional difficulties arise due to changes in the surface structure and changes in its temperature. During the fire, soot is deposited on the surface, varnish peels off and the metal is coated with oxide. These processes cause a change in emissivity. The emissivity of the surface depends on the temperature of the object, and this changes during the fire. The available literature data on emissivity refers to clean surfaces and to stable laboratory conditions, therefore they have little importance and use in fire conditions. During conducted test measuring field, to which the thermovision camera lens was directed, was designated on the body surface. The measuring area was selected on the car door. A thermocouple was installed in the area of this field. Parallel temperature measurements were made by these devices. Measurements with a thermal imaging camera were made initially with the assumed emissivity value $\varepsilon=1$. Graphs of temperature determined by 
these two methods were made and the emissivity value at which the correlation of the graphs is the highest was chosen. The best correlation was obtained for emissivity $\varepsilon=0.83$.

\section{Conclusions}

From the point of view of carrying out the rescue and firefighting operation, two main factors influencing the development of a passenger car fire dynamics are significant. The first is the fire duration, on the basis of which it is likely to predict that in the first ten minutes there will be no full flashover. The second factor is the temperature of the glass panes and the material from which they are made. The moment when the windows fall out heralds a quick flashover of the burning car. The thermal imaging camera is very helpful in fire development tests. It allows measuring the surface temperature of the wall, body, glass without any time delay. The operator is safe because he can be located at a considerable distance. The camera has some disadvantages as well. The biggest one is the need to know the surface emissivity. Each object has a different emissivity that changes during a fire. The article proposes a method that allows determining the approximate emissivity value for a complete combustion cycle. Some effects that occur during a fire, such as explosions of structural elements, destruction of glass panes, are better visible in infrared, especially in the dark, smoke, fog.

\section{References}

1. A. Szajewska, Termowizja w ochronie przeciwpożarowej (SGSP, Warszawa, 2018)

2. F. Amon, A. Hamins, N. Bryner, J. Rowe, Fire Safety J. 43, 541 (2008)

3. F. Amon, A. Ducharme, Fire Techn. 45, 313 (2009)

4. R. Downey, Fire Eng. 6, 24 (2000)

5. R. Gade, T.B. Moeslund, Machine Vision and Applications 25, 245 (2014)

6. T. Suzuki, T. Tsuruda, K. Yamaguchi, Y. Iono, M. Honjo, D. Miura, Association for Fire Safety Sci. AOFST 7 (2007)

7. S. Hittle, K. Niemann, Fire Eng. 7 (2012)

8. A. Szajewska, J. Rybiński, K. Barbasiewicz, Logistyka 5, 1519 (2015)

9. A. Szajewska, Proc. Eng. 172,1067 (2017)

10. K. Okamoto, N. Watanbe, Y. Hagimoto, T. Chigira, R. Masano, H. Miura, S. Ochiai, H. Satoh, Y. Tamura, K. Hayano, Y. Maeda, J. Suzuki, Fire Safety J. 44, 301 (2009)

11. K. Okamoto, T. Otake, H. Miyamoto, M. Honma, Fire Safety J. 62, 272 (2013)

12. B. Merci, M. Shipp, Fire Safety J. 57, 3 (2013)

13. M. Slimonowa, P. Polednak, Pozarni ochrana VSB -TU, 324 (2010)

14. B. Zhao, J. Kruppa, Fire Mat. 28, 269 (2004)

15. M. Shipp, M. Spearpoint, Fire Mat. 19,143 (1995)

16. B. Sygit, P. Guzewski, Prokuraura i Prawo 10,175 (2014)

17. A. Szajewska, 13th Quantitative Infrared Thermography Conference, 10.21611/qirt.2016.166, 1006-1011 (2016) 